\title{
Liminality in preregistration mental health nurse education: a review of the literature
}

\begin{abstract}
This paper provides an analysis of the anthropological concept of liminality in relation to undergraduate preregistration mental health nurse education, and considers implications both for students and nurse educators working in this field.

A review of educational and professional literature was undertaken in order to clarify the concept of liminality within the context of nurse education to aid in understanding how nurse educators could maximise the potential of liminality within the mental health pre registration nursing programme, and to consider the relationship between liminality and the preparation of future mental health nursing practitioners.
\end{abstract}

A survey of the findings and conclusions of the selected studies yielded two key areas in within which the concept has an explanatory function: in relation to "threshold concepts" in nurse education and as a way of describing a stage in the development of a role and identity.

Discussion of each of these areas points to suggestions for changes in the understanding of education and training for mental health nurses, particularly in the context of the United Kingdom.

Keywords: Liminality, Turner, threshold concept, mental health nurse

\section{INTRODUCTION}

Over the past two decades mental health nursing has adopted a largely psychiatric or medical discourse as the basis of practice with the possibility that nursing care has been reduced to 
dispensing medication, controlling the behaviour associated with mental distress until the medication takes effect, and helping patients adapt to a life of disability as a result of a biochemical imbalance (Crowe and Alavi 1999). Voices from within nursing education have been urging that we move away from the "era of the biologist" and the "era of the bureaucrat" (Happell 2008) where "pathology pays" (Flaskerud 2012) and again embrace the psychodynamic, humanistic and interpersonal foundations of mental health nursing (Gallop and O Brien 2003; Happell 2008; Lipscomb and Ishmael 2009). Jones (2012) stated: "Now more than ever, we need the structure of an interpersonal paradigm, such as that proposed by Peplau, to guide curricula of professional nursing practice. We need to remember and reclaim was is rightfully a significant if not a key element to the nursing profession" ( $\mathrm{p}$ 168), clearly suggesting that this fundamental aspect of nursing has been lost along the way, buried under nursing's struggle with defining itself as an academic discipline with a clear professional identity distinct from medicine and psychiatry (Gerrish et al 2003; Carr 2007; Andrew 2012), propelled by the drive to deliver evidence based and quantifiable results in order to meet targets.

So, as practitioners may have been at risk of being taken ever closer to the medicalisation of human distress, the consequences for the patient are even more disturbing, as the result is "a style of care that many patients find coercive and dehumanising" (Bentall 2009 xvii). This narrowing of roles seems particularly inappropriate in relation to mental health nursing, because it is by definition a person-centred and interpersonal field of practice that resists reduction to simple procedures. An understanding of liminality may be of value in aiding student mental health nurses gain a better appreciation of the challenges and opportunities this phenomenological position presents.

If we accept Barker's view that the world of human distress "is infinitely richer than any of its explanatory models or theories" (Barker 1999 p1), it therefore requires that the education of mental health nurses should place emphasis on their socialisation into a role and a way of relating to patients as well as a set of functions. This in turn requires that mental health nurse education be transformational in terms of social role and function as well as at the level of knowledge, 
competence and academic ability. Nursing care which positions the individual's experience of mental distress and the thresholds to be negotiated on the journey towards recovery as central must be underpinned by an educational process which is conducive to this.

Liminality, as classically advanced by the French ethnographer Arnold van Gennep (original 1909; English translation 1960) and developed in the work of the anthropologist Victor Turner $(1967 ; 1969)$ provides a useful category within which to consider this transformational activity. Van Gennep studied "rites of passage" (transitional rituals) in a range of cultures. He described such rituals as having a three-part structure: separation (preliminal phase), liminal period (from the Latin "limen", meaning threshold), and reassimilation (postliminal phase). For him, the major role of the liminal period was to enable a transition in the individual from one status to another in society; and to supply a psychological, social and territorial "space" in which the individual may be prepared for their new role and status. Turner built upon and expanded the notion of the liminal phase by analysing rites of passage within tribal systems; most famously the Ndembu tribe in Africa. He concluded that liminality is a place "betwixt and between" where the status of liminal individuals is socially and structurally ambiguous; this is a realm of "pure possibility" (Turner 1967); "a time of enchantment", when "anything might, even should, happen" (Turner 1979 p 465, original emphasis). Here, events, experience and knowledge intermingle and are juxtaposed in new ways, leading to new learning (Turner 1967). Turner explores the effects of liminality in interpersonal and social interactions, and establishes that within the liminal phase alternative modes of social relatedness appear (Rubenstein 1992). The most common of these is what Turner (1969) identifies as communitas, which occurs when groups of liminal individuals come together having equal social status and recognise the core humanity and values they share. Marginality and structural inferiority are also consequences of liminality and have relevance to mental health nursing practice, but are not explored in detail within this paper. 
The significance of the idea of a "rite of passage" is that it presents the educative process as discontinuous and transformational rather than incremental: the individual does not gradually grow into a new role but has to first abandon old certainties and perspectives, entering a time of uncertainty and apparent chaos before acquiring a new identity. It thus provides a framework for an educative process in which a period of uncertainty and confusion - a liminal space - is inevitable, rather than one in which it should be avoided. Thus, the concept of liminality may designate the productive role of an experience of confusion, both within the educative process and in the practice of mental health nursing.

Furthermore, it may not be possible or desirable to expect one single knowledge structure to explain the nature of mental health nursing. Cutcliffe (2007) suggests that there are two types of psychiatric nurse perhaps best represented by the manifestation of the psychodynamic v's pathology paradigms of knowledge (McCabe 2002), often reflected in the micro level practices of individuals, and that each nurse has a duty to ask themselves which type of nurse they are. We propose that the "liminal space" may present both educators and students with an opportunity to consider their responses to this question.

The purpose of this paper is therefore not to establish an objective truth in relation to liminality in mental health nurse education, but rather evaluate the analytical value of this concept in an educational context. It will begin with a literature review which surveys the relevant research into the role of liminality in higher and professional education in general, and mental health nurse education in particular; themes and categories will then be derived from the literature recovered and used to structure a discussion of the role of liminality. Finally, the key findings of the discussion will be drawn together to consider pedagogical implications and form the basis of conclusions. 


\section{LITERATURE REVIEW}

The particular context of the authors is that of the nurse education and the National Health Service in the United Kingdom, a context which shapes all nursing education and therefore this literature review. A search of peer reviewed academic journals in English was conducted in the date range 1995 to 2013 because 1995 marked the point by which nurse education (Project 2000) had moved into the university setting in most areas of the England and Wales. The search was conducted using the terms "liminality, "Van Gennep", "Victor Turner" and "Higher Education" and "mental health nurse education" individually and in combination. Papers which were excluded from the search were those which focussed predominantly on: school children and educational practice; cultural and anthropological studies; liminal experiences of academics in transition (eg between roles); and doctoral students' experiences.

The first stage comprised a search of the following electronic databases: BEI, CINAHL, ERC, ERIC, Ethos, Internurse, JSTOR, OVID, PsychARTICLES and ScienceDirect. After selection and sorting by relevance, it yielded a total of 21 items.

In order to achieve both high recall and high precision (Shaw et al 2004), this approach was supplemented with ancestry searches, hand searches, citation searches and additional internet searches, increasing the total to 27 . A closer analysis of content reduced this number to 13 which form the basis of the discussion below.

Critical reading and analysis of these papers using an adaptation of Srivastava's (2005, in Srivastava and Hopwood 2009) Iterative Framework for Qualitative Data Analysis suggests that the concept of "liminality" is represented in a numbers of ways, which are present in different combinations across the literature recovered.

No studies were retrieved with a specific focus on mental health nurse education, and so any conclusions drawn from the literature were carefully considered by the authors in light of this. 


\section{Liminality in the literature: clarifying the concept}

Many of the studies in this review do not have liminality as their main focus, and some merely offer a description of the concept within the introductory sections of the papers in order to provide a background and context for the primary aim of the study-for example, examining threshold concepts and practices (Meyer and Land 2003, Clouder 2005, Gourlay 2009), professional socialisation (Holland 1999, Clouder 2003), transition into first year in higher education (Palmer et al 2009), transition into first year undergraduate nursing (Andrew et al 2009) and student identity (Field 2012). However, within these studies, the authors often returned to comment further on the possibilities and potential of liminality in their discussion or conclusions, and liminality appears as a conceptual thread within many of the articles. Other studies (Hurlock 2008, Cook- Sather and Alter 2011) are more explicit about the notion, and seek to examine more specifically what liminality means and how it can provide a framework within which to understand different educational or transitional experiences.

Holland (1999), Barton (2007) and Andrew et al (2009) all draw on Van Gennep's Rites of Passage (1960) in relation to transition within nurse education. This revealed that there is a degree of interest in the application of social role transition theory in nursing, but although these studies all acknowledge the liminal phase, they do not aim to explore the notion in any depth.

Meyer and Land's theoretical paper (2005) builds upon their earlier work (2003) which introduced the notion of threshold concepts and troublesome knowledge within disciplines, and offers the suggestion that conceptual spaces occupied by students in higher education, particularly when these students find the learning of certain concepts troublesome or difficult are "akin to states of liminality" (p375). Gourlay (2009 p184) suggests that the concept of liminality is best known in higher education directly as a result of Meyer and Land's work on threshold concepts; this is supported by the fact that Clouder $(2005)$ drew heavily on Meyer and Land's work $(2003,2005)$ to examine caring as a threshold concept; Hurlock et al (2008) later made reference to Clouder's 
interpretation of threshold concepts (derived from Meyer and Land), in their case study of social work field education; Wallace (2010) considers threshold concepts in relation to adult literacies, and Gourlay (2009) proposes academic literacies as threshold practices, which would benefit from a "liminality analysis" (p189) in order to better understand the transitions some students may experience in developing their academic writing skills.

Hurlock et al (2008) offer the most detailed and illuminating examination of the concept of liminality as applied to professional education in their hermeneutic interpretation of interview and email data gathered over a five month period from Tina, a senior social work student. The paper explores in depth the "unsettling liminal space" (p293) of the student's personal and practice experiences, and her movement from liminality into natality, or "crossing a threshold" (Clouder 2005). In particular, the suggestion that Tina's experience of the liminal space, with its ambiguity, uncertainty and chaos may prepare her for the "swampy ground ...of professional practice" (Dunne 2001 in Hurlock et al 2008) mirrors very closely Mary Gobbi's (2005) view of nursing knowledge as "messy" and "idiosyncratic" ( 121 ). Hurlock 's study provides an extremely useful lens through which to view the liminal space - as a time of preparation for a profession in which students and practitioners may experience dissonance and conflict at the intersection of theory and practice, involving possibly unsettling separation from previous values and belief structures and incorporating emerging new professional identities. We suggest that this perspective captures the essence of liminality as part of a more protracted process, situated "betwixt and between" (Turner 1967) the preliminal or separation stage, and the postliminal incorporation phase - the latter being akin to Tina's experience of natality (Hurlock et al 2008).

Clouder (2005) suggests that the Latin origins of the term, coupled with difficulty in "making tangible a transformative period in space/time that captures the flux of uncertainty makes the term itself seem obscure" (p507). This perceived obscurity may go some way to explaining why none of the articles reviewed questioned the essential nature or existence of liminality; hence there was no 
critique or evaluation of the concept per se. It appears therefore, that liminality has become an accepted, though arguably vague at times, concept which now provides a theoretical framework for scholars to work within, allowing interpretation and application of the idea across a range of disciplines and activities including such diverse subject areas as threshold concepts within and across disciplines such as economics, mathematics, physics and cultural studies (Meyer and Land 2003), adult literacies (Wallace 2010), first year undergraduate transition into university environments (Palmer et al 2009) and social work field experience (Hurlock et al 2008).

It is worth highlighting the sometimes subtle differences in the language used by authors to represent liminality within their studies. For example, Cook-Sather and Alter (2011) refer to a "liminal position" in their qualitative study of students undertaking a pedagogical consultant role in faculty development; whilst Field (2012), writing about student identity, refers to "liminal persons" and proposes the idea of a "liminal identity" as a helpful way to understand student experience. Barton (2007) refers to a "liminal phase"; Wallace (2010) to a "liminal state" and a "liminal stage" at different points in his paper. The authors' choice of language may just be a question of semantics, but it appears the positioning of "liminality" may be dependent upon the perspective from which it is viewed. Thus, liminality has been positioned as a temporal (Holland 1999, Barton 2007) and spatial construct (Hurlock et al 2008); a "suspended state" (Meyer and Land 2003 p13, Cook- Sather and Alter 2011) and a "vantage point" that can be both literal and figurative (Cook-Sather and Alter 2011 p41). Palmer et al (2009) see students as "...suspended in a transient space..." whilst they adjust to the first year at university (p40). It is interesting that both Holland (1999) and Barton (2007) approach the subject from a nurse educator/practitioner perspective undertaking research with undergraduate students, and both locate liminality temporally. Meyer and Land (2005) provide a very useful observation which may help to explain this. They note the difference between the "teleological nature of undergraduate learning compared with the more liminally engaged nature of post graduate research" ( $p$ 380), suggesting perhaps that when there is a linear process or "epistemological steeplechase, towards a preordained end" (p379), there is less opportunity for 
students to remain in the liminal space. Furthermore, undergraduate nurse education programmes are subject to significantly more clearly defined expectations and predetermined outcomes than other higher education programmes (due to validation and monitoring by the regulatory body) so there is a risk of creating registrants who appear professionally socialised- having "learnt to play the game" (Clouder 2003 p217) but may not have lingered long enough in the liminal space for real transformation to have occurred.

Establishing a clear definition of liminality therefore is challenging given the range of contexts in which it has been employed, but this perhaps mirrors the "universality" of Van Gennep and Turner's ideas (Barton 2007). As Turner makes clear, liminal time is not controlled by the clock, but is a "time outside of time" (Turner 1982 p253), and is "betwixt and between" all fixed points of classification: an intersection, a crossroads, a "hyphenated space", that is "haunted and generative" (Jardine 1998). Wallace's conclusion ultimately seems the most helpful as he suggests that "the state of liminality will be experienced differently by every student..." (2010 p11).

Overall, the literature reviewed is faithful to Turner's original conceptualisation of liminality, takes a reflexive and responsive approach to its interpretation and use as a theoretical framework, and presents a consistent picture of the ambiguous character of liminality. By accepting this fluidity it can be argued that this allows for maximum flexibility in interpretation and application of Turner's (1969) ideas. Indeed, it seems that the very definition of liminality is represented in its qualities- it is ambiguous, defying classification, anti structural; full of possibilities and potential. Perhaps achieving absolute clarity with such a 'shapeshifting' temporal/spatial concept as liminality is best left for individuals to determine for themselves.

Further analysis of the selected studies indicated that the concept of liminality was deployed in two distinct ways: 
1. To describe "threshold concepts" as a stage in the learning process, when the student is confronted with unfamiliar and possibly threatening ideas; and negotiating them develops a new level of insight.

2. To describe a stage in the "initiation" of a new member of the professional community; the adoption and internalisation of the professional role, an essential stage to negotiate if the student is to adopt a professional identity.

The remainder of this paper will discuss these themes in turn, before summarising their significance for a pedagogy for student mental health nurses and drawing conclusions.

\section{DISCUSSION}

\section{Liminality and threshold concepts}

The notion of liminality as representing a threshold is a repeated theme in the literature, and finds resonance with Mezirow's work which suggests that a learning sequence is established as a result of a discordant experience (one that is not in harmony with prior experience or assumptions): when the student's "meaning perspective" can no longer contain and make sense of the situation in which they find themselves (Mezirow, 1977 in Jarvis 1995). Meyer and Land maintain that there are "portals" or thresholds in each discipline that are transformative and open up new and previously inaccessible ways of thinking (2003 p1); and in their later theoretical paper (2005) offer the suggestion that conceptual spaces occupied by students in higher education, particularly when these students find the learning of certain concepts troublesome or difficult are "akin to states of liminality" (Meyer and Land 2005, p375) in which students may find themselves "stuck"e (p377). Similarly, Gourlay (2009) suggests that an understanding of liminality allows 
educators and learners to accept that the emotional struggles in transition are something to be expected, a normal part of the academic process, rather than a problem or a welfare issue (p 189). (See also Clouder 2005; Hurlock et al 2008; Wallace 2010 ).

When a student successfully negotiates a liminal stage, the effects are likely to be permanent. Indeed Meyer and Land (2003) equate mastery of threshold concepts with deep and long lasting learning, and Wallace suggests that once in the postliminal stage with reflexivity established, it, "cannot be readily set aside" (2010 p11). Clouder (2005) also concludes that the negotiation of a threshold is irreversible because experiences of caring (identified by her as a threshold concept) are profound and are therefore not likely to be forgotten or unlearned ( $\mathrm{p} 513)$.

Conversely, the discomfort which is an essential characteristic of the liminal phase may explain why some students engage in "mimicry" or "faking it", without discovering liminality's "personally transformative potential" (Cousin 2003 p9). Cousin believes that conventional academic testing risks this happening when assessing certain complex and challenging concepts and thus any assessment strategy should be designed with this risk in mind.

Gourlay (2009), and Hurlock et al (2008), comment on the need for educators to allow students to fully experience this unsettling period, rather than needing to "foreclose their experience" (Hurlock et al 2008 p297). This "foreclosure" may be well intentioned, but could inhibit learning. Meyer and Land (2005) warn against intervening in liminality in the context of threshold concepts and troublesome knowledge, suggesting that if educators attempt to simplify threshold concepts for students by introducing a "naïve version of a threshold concept" (p381), this often only serves to act as a proxy, and can result in the student 
setting out on a path of ritualised knowledge which can ultimately prevent the learner actually crossing the threshold of the concept (p381).

It follows from this that, although possibly worrying for educators and distressing for students, "liminal" moments are to be welcomed as opportunities for growth rather than minimized as interruptions in the learning process. Wallace (2010) argues that the preliminal state is one of "limited knowledge and narrow experience" characterised by "nonreflexive observation and unchallenged assumptions" (p9) that must be left behind in order to cross a threshold and enter the liminal phase, and it is this aspect which is most challenging and unsettling; meeting resistance, defensive rejection, blocking or distortion in the learning process (Illeris 2007), and can involve "uncomfortable emotional repositioning" (Wallace $2010 \mathrm{p} 11$ ).

\section{Liminality, Identity and professional socialisation}

The concept of a discontinuous transition represented by the notion of "liminality" has implications beyond acquiring new knowledge: there is an ontological dimension to education, it is not "solely an epistemological endeavour" (Hurlock et al 2008 p295). As well as the thresholds within learning, there is a transition of the student's self-understanding, role and status which is most clearly marked at the point where they prepare to enter professional practice.

One particular form of the "rite of passage" is Higher Education itself, in which "being a student" can be the liminal experience between one state and another (Field 2012). Field (2012) proposes that students may adopt a "liminal identity" (p4) characterised for some by "imposter syndrome" (Palmer et al 2009 p 47) - akin to the "marginality" that Turner (1969) 
associates with liminality - as they respond to and are influenced by the social and cultural dynamic in higher education.

This transition can be complicated for student nurses by two factors: on the one hand, as students on a professional higher education programme, they have to adapt to both an academic and professional environment when they commence their course, and need to do so quickly (Andrew et al 2009), the emergence of a liminal identity is even more probable. As they try and meet the expectations from professional mentors and educators, as well as undergoing the transitions inherent in commencing higher education in general (Palmer et al 2009) they may be subject to a more acute manifestation of liminality. This, along with other more widely studied factors may go some way to accounting for high rates of attrition in first year nurse education. In addition, if student nurses maintain employment in a health care support role whilst undertaking their training, they may be hindered from making the transition and experience "role duality" (Holland 1999 p 233). Within this professionaleducation environment, the passage through the liminal phase into new identity must be managed with some care. Thus Holland (1999) refers to socialisation into a new role that "...involves learning the cultural rules..." (p229), which are themselves unwritten, and form part of the implicit curriculum (Eisner 1985).

This suggests there is far more expected of the student in practice placements than is represented by the successful completion of clinical competency documents, and relates equally to demonstrating some attitudinal or identity shifts in order to become an accepted member of a profession. Andrew et al (2009) note that as early as the first clinical placement, student nurses need to know that they belong, and to be encouraged to adopt the behaviour proper to nurses (p18). Clouder (2003), using data derived from her study of occupational therapy students, speaks of placements as an opportunity for "learning to play 
the game" since the rules of behaviour are more tightly prescribed in practice than among university students (p.217). She speaks of socialisation as "presentation of self" (p218), adopting behaviours which elicit positive feedback from practice educators and mentors and can eventually lead to an altered sense of identity (Clouder 2003).

A successful transition is described by Barton (2007) who found that post qualifying nursing practice students experienced identity loss in leaving their old role (the preliminal phase), but established a shared identity, a communitas characteristic of the liminal phase, which was later noted to decline when students entered the postliminal phase (reassimilation), as their self reliance and confidence in their emerging new identities became evident (Barton 2007). In other words, there is a sort of group solidarity among students, but this falls away as each has to negotiate their transition into a new role and identity. Barton's sample were qualified nurses who may have exhibited the traits found by Clouder amongst some of her sample students (older than their peers, with prior life and work experience) who experienced less need to think strategically ("play the game") in their fieldwork placements, and where individual agency was evident in their capacity to negotiate the culture of the workplace, demonstrating autonomy and independence- both qualities which may enhance the capacity to negotiate transitions effectively.

These transitions are of interest and importance in mental health nurse education because they must be successfully negotiated before a professional role and identity is internalised. Since this is a costly process for the student, it is possible to foresee at least three ways in which it may break down. First, as noted, for some student nurses the intensity of role conflict may be too intense because they are attempting to maintain their old ("preliminal") 
identity while negotiating a new one at University. Secondly, there is an important role for communitas in the student body. But if that shared spirit of solidarity over-against the outside world does not breakdown as intended as students are reassimilated into the professional community, it has the potential to insulate its members against the demands and expectations of their role. In other words, it can impede the transition into professional life. Finally, there is a risk that the student will simply "play the game" without internalising its lessons. For these reasons, there is a need to monitor the process of role transition both within and beyond the period of training.

\section{PEDAGOGICAL IMPLICATIONS FOR STUDENT MENTAL HEALTH NURSES}

Hurlock et al (2008) suggest that Tina's experience of the liminal space, with its ambiguity, uncertainty and chaos may prepare her for the "swampy ground ...of professional practice" (Dunne 2001, in Hurlock et al 2008 p294). Similar notions inform the perspectives of Gourlay (2009) and Meyer and Land (2005): person-centred professional practice is necessarily difficult to define and control, involving open-ended commitments, structural uncertainty and the suspension of expectations.

This raises the question of whether mental health nursing itself takes place in a "liminal space"; an "interstitial crack" outside traditional rules (Belk 1997).

If so, then education for mental health nursing requires preparing students to tolerate the uncertainties and stresses of working in just such a liminal space. This is a suggestion that is implicit in the literature recovered, but not developed in an explicit or systematic way. Nevertheless, it deserves consideration as a potentially important way of understanding the role of liminality in mental health nursing. 
In the practice area students will be exposed to some of the most vulnerable members of society; they will witness extremes of mood and associated behaviour and be expected to deal with hostility, aggression, suicidal acts, acute psychosis, effects of trauma, abuse and addiction, end of life care to name a few. Many patients who are unwell totally reject care, and in the UK treatment can be forced against their will if under a section of the Mental Health Act $(1983,2007)$. In these ways psychiatric inpatient facilities can be understood as themselves liminal spaces, occupied by individuals experiencing their own liminality: often "betwixt and between" (Turner 1967) mental health and mental illhealth; stuck between being a "free agent" and a detained patient; oscillating between insight and loss of insight; arguably, "places of danger" (Belk 1997) or places of safety and possibility (Turner 1967). By analogy with Jackson's (2005) paper focussing on stigma, liminality and chronic pain, patients with mental illhealth may be understood to "transgress the categorical division between mind and body and to confound the codes of morality surrounding sickness and health . . . as liminal creature[s] whose uncertain ontological status provokes stigmatising reactions in others" (Jackson 2005 p.332, 333). This experience can be disturbing and unsettling for the student, and there may be a temptation by mentors and educators to "spare" the student exposure to some of the most challenging situations, thus prompting foreclosure of the learning.

\section{SUMMARY OF THE LITERATURE}

This analysis of the use of the concept of liminality in the literature and how this might relate to the education of mental health nurses has uncovered three senses in which it is employed. In each of these it serves to mark and hold up to the light an aspect of nurse 
education that resists reduction to predictable and non-threatening procedures, instead relying on a phase of uncontrollability and, perhaps, disorientation if transformation is to take place.

First, transformative education in caring professions generally seems to rely upon liminal phases, "threshold concepts" which challenge the student's established frame of reference and invite them to a more profound understanding of their profession. Typically, this transition is accompanied by some discomfort and educators may be tempted to foreclose (Hurlock et al 2008) a student's experience of liminality in order to render the learning process easier. The implication of the findings surveyed above is that such a strategy would prevent a student from engaging in deep learning and in the personal changes this entails. Secondly, socialisation into a professional role is itself a rite of passage and includes a period of personal challenge, uncertainty and adjustment. The research surveyed demonstrated the personal cost of this process for the student, and also the risk that they might avoid the challenge by dropping out; by retreating into the communitas of the student group; or by "going through the motions" without properly internalizing the role they are required to adopt. Particular attention needs to be paid to these possibilities during the placement process, and student assessment must take careful account of the risk of a superficial socialization into the role.

Finally, some implications from the research speculates on the liminal character of mental health nursing itself. On analysis, this liminality may be understood to have two dimensions: as fundamental to nursing as an interpersonal process that requires commitment on both sides; and as a result of the attempt to maintain a properly interpersonal practice within a profession that may easily retreat into mechanistic and functionalist models of nursing. This suggests that the student experience of liminality is not simply an element of their training 
or a process to be endured prior to registration, but a preparation for the ambiguities, costs and anxieties attendant on mental health nursing practice in general. Normalising the liminal experience is suggested as a measure to help students with the challenges and opportunities presented by liminality (Gourlay 2009).

\section{CONCLUSION}

As well as occupying the "liminal space" of the mental health service, students and new registrants may find themselves marginalised by their commitment to person-centred care as the development of this caring practice may be at odds with the prevailing culture within the profession itself as illustrated by scandals such as that of Mid Staffordshire (2013) Unfortunately, some students are assimilated into these systems in an unreflective way almost before they realise it. Many more identify with patients more closely and are troubled by where they might fit into their caring profession. Thus, to be fully committed to person-centred care, the student must be prepared for two sorts of liminality: that related to the process of mental health nursing care in general, in which it is not possible to limit all uncertainties and risks; and that arising from their refusal to settle for a philosophy of nursing which reduces care to a series of remote functions and instrumental interventions. Both of these areas would benefit from further research. 


\section{REFERENCES}

Andrew, N., 2012. Professional identity in Nursing: Are we there yet? Nurse Education Today $32(8), \quad 846-849$

Andrew, N., McGuinness, C., Reid, G., \& Corcoran, T., 2009. Greater than the sum of its parts: Transition into the first year of undergraduate nursing. Nurse Education in Practice 9, $13-21$

Barker, P., 1999, The need for psychiatric nursing: towards a multidimensional theory of caring. Nursing Inquiry 6, 103-111

Barton, T., 2007, Student nurse practitioners- a rite of passage? The universality of van Gennep's model of social transition. Nurse Education in Practice 7, 338-347

Belk, R. W. 19972 Been there, done that, bought the souvenirs. Consumer research: Postcards from the edge, 22.

Bentall, R., 2009 Doctoring the Mind. New York: New York University Press

Carr, G., 2007, Changes in nurse education: being a nurse teacher. Nurse Education Today $27,893-899$

Clouder, L., 2003, Becoming professional: exploring the complexities of professional socialisation in health and social care. Learning in Health and Social Care 2 (4), 213-222 
Clouder, L., 2005 Caring as a "threshold concept": transforming students in higher education into health(care) professionals. Teaching in Higher Education 10 (4), 505-517

Cook-Sather, A., \& Alter, Z., 2011, What is and what can be: how a liminal position can change learning and teaching in higher education. Anthropology and Education Quarterly 42 (1), 37-53

Cousin, G. 2003 Threshold concepts, troublesome knowledge and learning about others', Paper presented to the 10th Conference of the European Association for Research on Learning and Instruction (EARLI), Padova, Italy, August 26-30.

Crowe, M., \& Alavi, C., 1999, Mad talk: attending to the language of distress. Nursing Inquiry 6 (1), 26-33

Cutcliffe, J., 2007, The die has been cast? Rediscovering the essence of psychiatric nursing. Nurse Education Perspectives 28 (4), 209-213

Eisner, E. W. 1985, 'The Art of Educational Evaluation', London: Falmer.

Field, J., 2012, Transitions in lifelong learning: public issues, private troubles, liminal identities. Studies for the Learning Society 2 (3), 4-11

Flaskerud ,J 2012 DSM V: Implications for mental health nursing education. Issues in Mental Health Nursing 33 (9) 568-576 
Gallop, R \& O Brien, L 2003 Re establishing psychodynamic theory as foundational knowledge for psychiatric/mental health nursing care. Issues in Mental Health Nursing Care 24 (2) 213-227

Gerrish, K., McManus, M., \& Ashworth, P., 2003, Creating what sort of professional? Master's level nurse education as a professionalising strategy. Nursing Inquiry 10 (2), 103112

Gobbi, M., 2005, Nursing practice as bricoleur activity: a concept explored. Nursing Inquiry $12(2), 117-125$

Gourlay, L., 2009, Threshold practices: becoming a student through academic literacies. London Review of Education 7(2) 181-92

Holland, K., 1999, A journey to becoming: the student nurse in transition. Journal of Advanced Nursing 29(1), 229-236

Happell, B. 2008 Notes from conference presentation: Australian Congress of Mental Health Nursing Conference, Melbourne 2008

Hurlock, D., Barlow, C., Phelan, A., Myrick, F., Sawa, R., \& Rogers, G., 2008, Falls the shadow and the light: liminality and natality in social work field education. Teaching in 
Higher Education 13(3), 291-301

Illeris, K. 2007 How we learn: Learning and non-learning in school and beyond. London: Routledge.

Jackson, J 2005 Stigma liminality and chronic pain: mind-body borderlands. American Ethnologist 32 (3) $332-353$

Jones, J., 2012 Has anybody seen my old friend Peplau? The absence of interpersonal curricula in programs of nursing. Archives of Psychiatric Nursing 26(3), 167-168

Lipscomb M \& Ishmael A 2009 Humanistic educational theory and the socialisation of preregistration mental health nursing students International Journal of Mental Health Nursing 18, $173-178$

McCabe, S., 2002, The nature of psychiatric nursing: the intersection of paradigm, evolution and history. Archives of Psychiatric Nursing 16 (2) 51-60

Meyer, J., \& Land, R., 2003, Threshold Concepts and Troublesome Knowledge 1 - Linkages to Ways of Thinking and Practising in C.Rust (Ed) Improving Student Learning - Ten Years On. OCSLD, Oxford 412-424

Meyer, J., \& Land, R., 2005, Threshold concepts and troublesome knowledge (2):

Epistemological considerations and a conceptual framework for teaching and learning. Higher Education 49, 373-388 
Mezirow, J 1977 in Jarvis, P., 1995, Adult and Continuing Education - Theory and Practice Second Edition. London: Routledge\& associates

Palmer, M., O'Kane, P., \& Owens, M., 2009 Betwixt spaces: student accounts of turning point experiences in the first-year transition. Studies in Higher Education 34(1), 37-54

Report Of The Independent Inquiry Into Care Provided By Mid Staffordshire NHS Foundation Trust (2013) available online at http://www.midstaffspublicinquiry.com/report (first accessed 18 April 2013)

Rubenstein, J., 1992, Purim, liminality and communitas. AJS Review 17(2), 247-277

Shaw, R., Booth, A., Sutton, A., Miller, T., Smith, J., Young, B., Jones, D., \& Dixon-Woods, M., 2004, Finding qualitative research: an evaluation of search strategies. BMC Medical Research Methodology 4, 5

Srivastava, P., \& Hopwood, N., 2009, A Practical Iterative Framework for Qualitative Data Analysis. International Journal of Qualitative Methods 8(1), 76-84

The Mental Health Act 1983, 2007. Available at: www.legislation.gov.uk

Turner, V., 1967, The Forest of Symbols : Aspects of Ndembu Ritual. Ithaca, New York: Cornell University Press 
Turner, V., 1969, The Ritual Process: Structure and Anti Structure. London: Routledge and Kegan Paul

Turner, V., 1979, Frame, Flow and Reflection: Ritual and Drama as Public Liminality. Japanese Journal of Religious Studies 6 (4) 465-499

Turner, V., 1982, Images of Anti-Temporality: An Essay in the Anthropology of Experience. The Harvard Theological Review 75 (2), 243-265

Van Gennep, A., 1960, The Rites of Passage. London: Routledge

Wallace, D., 2010, The grit in the oyster-does an appreciation of threshold concepts in an adult literacies teaching qualification result in pearls of practice? From a conference paper October2008 in Literacy and Numeracy Studies 18 (1), 3-18 